\title{
Hidatidosis cerebral: comunicación de seis casos pediátricos
}

\author{
Martín Brizuela, Claudia Sarkis, Roberto González, Patricia Paulin, Fabiana Lubieniecki y Griselda Berberian
}

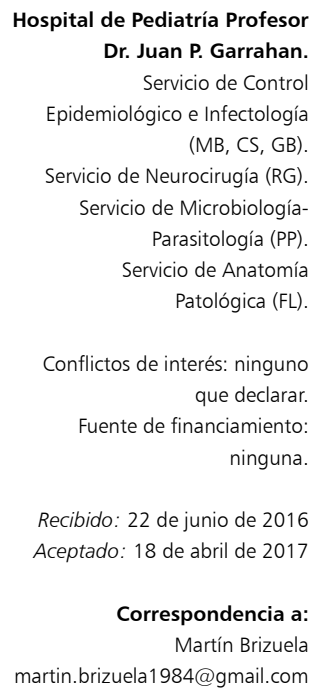

\section{Introducción}

$\mathrm{L}$ a hidatidosis es una infección parasitaria cuyo agente etiológico es Echinococcus granulosus ${ }^{1}$. Es una zoonosis y el ser humano se comporta como un hospedero intermediario accidental en el ciclo parasitario $^{1,2}$.

La localización hepática es la más frecuente, seguida por la pulmonar. La hidatidosis cerebral es inusual y representa entre 0,5 y $3 \%$ del total de casos. El $75 \%$ se produce en niños ${ }^{1}$.

Se presentan seis casos clínicos de pacientes con diagnóstico de hidatidosis cerebral internados en el Hospital de Pediatría J. P. Garrahan, entre los años 1992 y 2014.

El diagnóstico de hidatidosis se realizó en base a los criterios de la Organización Mundial de la Salud y del Ministerio de Salud de la Nación Argentina ${ }^{3,4}$.

\section{Caso clínico 1}

Preescolar de sexo masculino, con cinco años de edad, proveniente de una zona rural de la provincia de Santiago del Estero, zona de crianza de ganado bovino y con el hábito de alimentar a mascotas (perros) con sus vísceras. Consultó por ataxia progresiva y disminución de la agudeza visual de tres meses de evolución. La resonancia magnética $(\mathrm{RM})$ de cerebro mostró una lesión quística supratentorial temporo-parieto-occipital derecha de 7 $\mathrm{cm}$ de diámetro. La ecografía de abdomen y radiografía de tórax fueron normales. La serología con técnica de hemoaglutinación indirecta (HAI) para hidatidosis fue negativa. No presentó alteraciones en el hemograma ni en exámenes generales. Recibió tratamiento con albendazol hasta la resección quirúrgica completa del quiste. Se produjo la rotura intraquirúrgica del quiste sin complicaciones posteriores. La anatomía patológica confirmó la presencia de escólices de E. granulosus. Continuó con albendazol y praziquantel durante tres meses debido al accidente quirúrgico. Durante el seguimiento de 10 años no presentó focos secundarios ni secuelas relacionadas con la hidatidosis y la rotura del quiste.

\section{Caso clínico 2}

Escolar de sexo femenino, con siete años de edad, procedente de área urbana de Santiago del Estero. Sin antecedentes epidemiológicos de importancia. Consultó por hemiparesia facio-braquio-crural izquierda de un mes de evolución, asociada a una lesión quística infratemporal derecha en la TC de cerebro de $5 \mathrm{~cm}$ de diámetro. No tuvo compromiso hepático ni pulmonar. La prueba de HAI fue negativa para hidatidosis antes de la cirugía. No tuvo alteraciones en el hemograma ni en la función hepática al momento del diagnóstico. Inició tratamiento con albendazol 30 días previos a la cirugía, la que se realizó sin complicaciones. El estudio histopatológico confirmó la presencia de una lesión quística con escólices de E. granulosus en estadio de degene- 
ración. Presentó como complicación una hidrocefalia transitoria que no requirió tratamiento. Completó seis semanas post-quirúrgicas de albendazol con resolución ad integrum y sin secuelas.

\section{Caso clínico 3}

Escolar de sexo femenino, con siete años de edad, procedente de Río Negro. Vivía en una zona de crianza de ganado bovino, ovino y vacuno cercano a su domicilio. Consultó por convulsiones tónico-clónicas generalizadas de aproximadamente un año de evolución y una hemiparesia braquio-crural derecha de un mes de aparición. En la RM de cerebro se informó como un tumor supratentorial expansivo de $6 \mathrm{~cm}$ de diámetro, de localización subcortical temporo-parietal izquierdo que colapsaba ventrículos y desplazaba la línea media (Figura 1). Imágenes complementarias descartaron compromiso de otros órganos. La serología para hidatidosis por técnica de HAI fue negativa. No tuvo eosinofilia ni alteraciones en el laboratorio general. Inició tratamiento previo a la cirugía con albendazol por sospecha clínica e imagenológica de hidatidosis. Se realizó exéresis total del quiste. La anatomía patológica mostró una lesión quística con pared membranosa acelular, tinción de ácido peryódico de Schiff (PAS) positiva, en una de sus caras, con calcoforitos y restos celulares. Además, se observaron escólices con variables signos de necrosis y degeneración. La paciente presentó como secuela una hemiparesia facio-braquiocrural derecha que le dificultaba la deambulación.

\section{Caso clínico 4}

Escolar de sexo masculino, con 12 años de edad, procedente de Chaco, medio rural con hábitos de alimentación de canes con vísceras de ovejas y cabras. Consultó por un status convulsivo que se presentó una semana previa a la consulta. La RM de cerebro mostró una lesión quística cortico-subcortical frontal izquierda (Figura 2). Recibió tratamiento por sospecha de absceso bacteriano y/o parasitario con antimicrobianos y albendazol. Se descartó el compromiso hepático y pulmonar. Tuvo serología por HAI negativa para hidatidosis. Tampoco se detectó eosinofilia en su hemograma. Se realizó la exéresis completa del quiste. La anatomía patológica informó la presencia de una lesión quística con tres capas tisulares, una con extensa necrosis, calcificación y calcoforitos dispersos. La membrana celular anhista, PAS positiva, restos parasitarios calcificados, necróticos y con signos de degeneración, sin presencia de escólices viables. El paciente tuvo una buena evolución clínica, con recuperación neurológica completa.

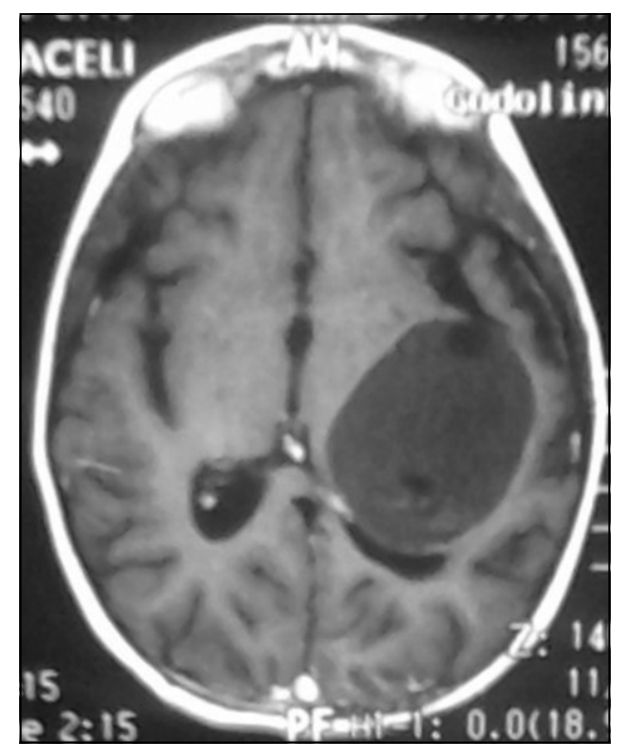

Figura 1. RM de cerebro que muestra lesión quística supratentorial expansiva de $6 \mathrm{~cm}$ de diámetro, subcortical temporoparietal izquierdo que colapsa ventrículos y desplaza la línea media.

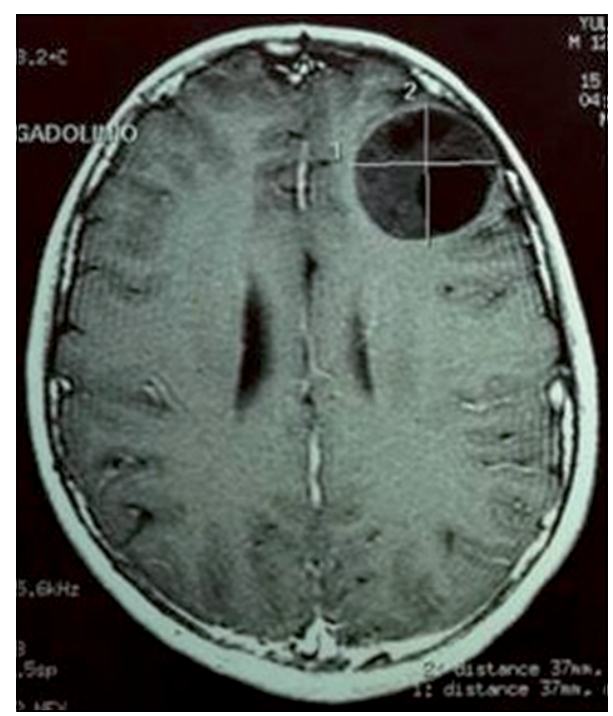

Figura 2. RM de cerebro muestra lesión quística cortico-subcortical frontal izquierda con contenido heterogéneo.

\section{Caso clínico 5}

Escolar de sexo masculino, con nueve años de edad, proveniente de la provincia de Buenos Aires, sin antecedente de cría de animales de granja ni de faenamiento. Fue derivado por sospecha de tumor quístico supratentorial. Tenía el antecedente de vómitos y cefalea de cuatro meses de evolución. Se realizó RM de cerebro que se informó con la presencia de una lesión quística a nivel supratentorial periventricular derecha que desplazaba la línea media. La ecografía de abdomen y la radiografía 
Figura 3. Aspecto macrocópico de un quiste hidatídico resecado quirúrgicamente.

Figura 4. Aspecto microscópico de un quiste hidatídico donde se observan las tres paredes que lo constituyen y la presencia de escólices.

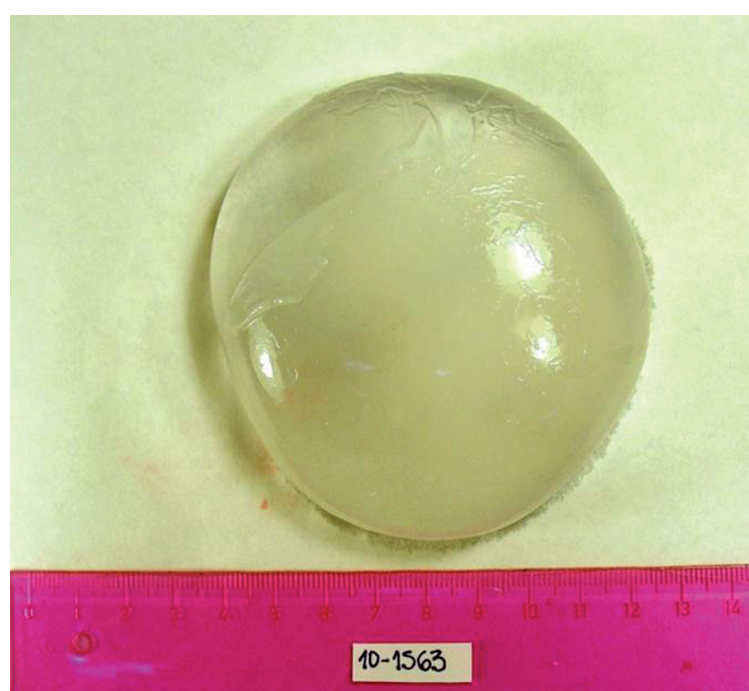

de tórax fueron normales. La serología por HAI para hidatidosis fue negativa. El hemograma no mostraba alteración significativa. Recibió tratamiento pre y postquirúrgico con albendazol. Se realizó la exéresis del quiste sin complicaciones (Figura 3). El estudio histológico describió una estructura quística con una pared con capa celular eosinófila (cutícula), germinativa y abundantes escólices (Figura 4).

\section{Caso clínico 6}

Preescolar de sexo masculino, con 4 años de edad, proveniente de Río Negro, sin antecedentes epidemiológicos de relevancia, que fue derivado por un tumor quístico infratentorial. Tenía el antecedente de cefalea y vómitos de cuatro meses de evolución a lo que se agregaron dos semanas previas al ingreso disminución de la agudeza visual, trastornos de la marcha y el lenguaje. La TC de cerebro mostraba una imagen quística con efecto de masa de $50 \mathrm{~mm}$ de diámetro a nivel del vermis y el hemisferio cerebeloso izquierdo con compresión y desplazamiento de las estructuras vecinas. Las paredes eran algo engrosadas y calcificadas y realzaban con el contraste en forma irregular. La ecografía de abdomen y la radiografía de tórax descartaron el compromiso de otros órganos. La serología por HAI para hidatidosis fue negativa y el laboratorio general no mostraba alteraciones significativas. En el acto quirúrgico se extrajo un quiste con dos capas, de aspecto gelatinoso con elementos calcificados en su interior. La anatomía patológica informó la presencia de escólices aislados de E. granulosus en distintos estadios de degeneración. Recibió tratamiento post-quirúrgico con albendazol.

\begin{tabular}{|c|c|c|c|c|c|c|}
\hline Característica & Caso 1 & Caso 2 & Caso 3 & Caso 4 & Caso 5 & Caso 6 \\
\hline Edad (años) & 5 & 7 & 7 & 12 & 9 & 4 \\
\hline Sexo & Varón & Mujer & Mujer & Varón & Varón & Varón \\
\hline Procedencia & Santiago del Estero & Santiago del Estero & Río Negro & Chaco & Buenos Aires & Río Negro \\
\hline Epidemiología & Sí & No & Sí & Sí & No & No \\
\hline Motivo de consulta & $\begin{array}{l}\text { Ataxia y disminución } \\
\text { de la agudeza visual }\end{array}$ & $\begin{array}{l}\text { Hemiparesia facio } \\
\text { braquio crural } \\
\text { derecha }\end{array}$ & $\begin{array}{l}\text { Convulsiones tónico } \\
\text { clónico generalizadas }\end{array}$ & Status convulsivo & Vómitos y cefalea & $\begin{array}{l}\text { Disminución de la } \\
\text { agudeza visual, tras- } \\
\text { tornos de la marcha }\end{array}$ \\
\hline Tiempo de evolución & 3 meses & 1 mes & 12 meses & 1 semana & 4 meses & 2 semanas \\
\hline Localización & $\begin{array}{l}\text { Supratentorial } \\
\text { temporo-parieto- } \\
\text { occipital derecha }\end{array}$ & $\begin{array}{l}\text { Infratemporal de- } \\
\text { recha }\end{array}$ & $\begin{array}{l}\text { Supratentorial } \\
\text { subcortical temporo- } \\
\text { parietal izquierdo }\end{array}$ & $\begin{array}{l}\text { Cortico- subcortical } \\
\text { frontal izquierda }\end{array}$ & $\begin{array}{l}\text { Temporal derecho } \\
\text { periventricular }\end{array}$ & $\begin{array}{l}\text { Infratentorial. Vermis } \\
\text { y hemisferio cerebe- } \\
\text { loso izquierdo }\end{array}$ \\
\hline Serología (HAI) & Negativa & Negativa & Negativa & Negativa & Negativa & Negativa \\
\hline Anatomía patológica & Sí & Sí & Sí & Sí & Sí & Sí \\
\hline Evolución & Sin secuelas & Sin secuelas & $\begin{array}{l}\text { Paresia faciobraquio- } \\
\text { crural }\end{array}$ & Sin secuelas & Sin secuelas & Sin secuelas \\
\hline
\end{tabular}




\section{Discusión}

La hidatidosis es la infección producida por el parásito E. granulosus cuyos hospederos definitivos son los animales caninos. Los ganados ovino, bovino y caprino intervienen como hospederos intermediarios. El hombre es un hospedero intermediario accidental al ingerir alimentos contaminados con materia fecal que contiene los huevos del parásito. Las larvas liberadas en el lumen intestinal del ser humano invaden el torrente sanguíneo y se diseminan a distintos órganos ${ }^{1,2}$.

El diagnóstico de la hidatidosis se basa en datos epidemiológicos, manifestaciones clínicas y métodos complementarios por imágenes. Las pruebas serológicas pueden ayudar al diagnóstico ${ }^{3}$. Tres de nuestros pacientes presentaron antecedentes epidemiológicos que orientaron hacia una hidatidosis como una posible etiología del cuadro clínico.

El diagnóstico de certeza se hace por la visualización macroscópica del quiste en el acto quirúrgico o de estructuras quísticas observadas microscópicamente ${ }^{3,4}$. En todos nuestros pacientes, el aspecto macroscópico de la lesión fue compatible con un quiste hidatídico. El estudio histopatológico confirmó el diagnóstico en los seis pacientes.

La hidatidosis debe sospecharse en:

- Toda persona con una masa quística (única o múltiple) en el abdomen, tórax u otra localización con antecedentes epidemiológicos.

- Toda persona con sospecha de hidatidosis por tamizajes poblacionales efectuados con ecografía ${ }^{3,4}$.

Se define como caso confirmado un caso sospechoso con confirmación diagnóstica por imágenes y/o diagnóstico serológico mediante ELISA, Western blot o hemoaglutinación indirecta (HAI) o por visualización directa por microscopia de protoescólices o ganchos del cestode, restos de membranas y/o estudio histopatológico de la pieza extraída por cirugía.

El hígado es afectado hasta en $90 \%$ de los casos, pulmón en 10-15\% y menos frecuentemente otros órganos como cerebro, ojo, músculos, riñones, bazo, etc. ${ }^{1}$.

La frecuencia de la hidatidosis cerebral varía entre 0,5 y $3 \%$ tal como se describe en los estudios de Turgut ${ }^{5}$, Kovoor $^{6}$ y Onal $^{7}$. La localización cerebral afecta hasta en $75 \%$ de los casos a niños.

Puede presentarse de dos formas según el mecanismo por el que las lesiones se producen en el sistema nervioso central: primaria o secundaria ${ }^{8}$.

La forma primaria corresponde a la presentación como quiste único localizado en el territorio irrigado por la arteria meníngea media. Mientras que en la forma secundaria hay múltiples quistes de cualquier localización asociados generalmente a compromiso de otros órganos ${ }^{8}$. Los seis casos presentados se presentaron como quistes de sistema nervioso central sin lesiones en otros órganos. En todos los casos se interpretó el cuadro como una hidatidosis cerebral primaria.

Puede presentarse con síntomas o signos de hipertensión endocraneal, convulsiones o signos de focalización neurológica ${ }^{1,2,9}$.

Duishanbai y cols. ${ }^{10}$, reportaron 30 casos de hidatidosis cerebral, donde las formas de presentación clínica fueron cefalea y vómitos $(87 \%)$ y hemiparesia $(30 \%)$. Otras formas menos frecuentes fueron trastornos visuales, ataxia cerebelosa, afasia y convulsiones. En los casos que aquí presentamos, los signos y síntomas más frecuentes fueron convulsiones y hemiparesia, ataxia y trastornos visuales.

La serología por técnica de ELISA es poco útil en esta localización, menos de $10 \%$ de los casos son positivos. Mientras que la técnica de HAI tiene una sensibilidad de $80 \%$ en la localización hepática y $65 \%$ en lesiones pulmonares ${ }^{3}$. No suele haber alteraciones en los estudios hematológicos habituales y su hallazgo es inespecífico ${ }^{1,2}$. En los niños que presentamos, la serología por HAI fue negativa y ninguno tuvo hemograma con eosinofilia; estos hallazgos son frecuentes en quistes hidatídicos intactos y en los de localización en sistema nervioso central. La eosinofilia es poco frecuente y puede aparecer cuando se produce la rotura del quiste o luego de la cirugía.

Las imágenes de sistema nervioso central por TC o RM permiten observar el quiste con una pared delgada, bien diferenciada del parénquima cerebral, en cuyo interior se pueden encontrar las vesículas hijas ${ }^{2,8}$. Los quistes suelen ocupar los hemisferios cerebrales. Khaldi y cols., comunicaron una serie de 117 casos de hidatidosis de sistema nervioso central en esta localización. Las formas secundarias pueden comprometer cualquier estructura del cerebro o cerebelo ${ }^{9}$. Los seis casos presentados tuvieron una TC de cerebro patológica con imágenes quísticas sugerentes con hidatidosis, localizadas en los hemisferios cerebrales y en cerebelo.

El diagnóstico diferencial infectológico es con abscesos bacterianos, neurocisticercosis, tuberculosis, coccidiomicosis, entre otros. Entre las causas no infecciosas pueden mencionarse el quiste aracnoide, quiste porencefálico y los tumores quísticos ${ }^{1,2}$. En nuestros pacientes se plantearon como principales diagnósticos a descartar, además de hidatidosis, un absceso cerebral bacteriano y tumores quísticos malignos o benignos. La confirmación etiológica se realizó en el acto quirúrgico por la biopsia por congelación en los seis casos, donde pudo observarse la presencia de escólices de E. granulosus.

El tratamiento de elección es la resección quirúrgica del quiste por la técnica de Dowling- Orlando ${ }^{1,5}$, que consiste en la exéresis total del quiste.

En la serie de casos de Turgut ${ }^{5}$, de 137 casos de hidatidosis intracraneana, el tratamiento definitivo consistió en la resección quirúrgica en $85 \%$ de los casos, produciéndo- 
se la rotura accidental del quiste en $25 \%$. Entre nuestros pacientes, todos los casos tuvieron resolución quirúrgica con dicha técnica.

En la serie de casos de Tuzun y cols. ${ }^{11}$, que incluyeron 25 niños sometidos a resección quirúrgica de los quistes hidatídicos cerebrales, $12 \%$ presentó la rotura del quiste durante el acto quirúrgico, sin desarrollo de anafilaxia. Otras complicaciones que se observaron fueron: neumoencéfalo (12\%), efusión subdural $(20 \%)$, hemorragia y hematoma epidural en menos de $10 \%$ de los casos. En nuestra serie, un paciente presentó como complicación la rotura accidental del quiste durante el acto quirúrgico. El paciente con rotura del quiste tuvo un seguimiento de 10 años, no presentando recaídas durante ese período de tiempo.

El antiparasitario de elección en la hidatidosis es albendazol. Su uso es controvertido y variable según la experiencia mundial. Previo a la cirugía reduciría el riesgo de diseminación de la enfermedad, la liberación de escólices viables y de líquido hidatídico que podrían generar reacciones anafilácticas mortales. Por otro lado, el tratamiento podría adelgazar la pared quística con el consiguiente riesgo de rotura durante el procedimiento ${ }^{5,9}$.

En la experiencia de Turgut $^{5}$ en Turquía, se empleó albendazol o mebendazol en $60 \%$ de los casos. Se indicó por rotura accidental del quiste o ante la imposibilidad de resolución quirúrgica por quistes múltiples.

Algunos autores recomiendan iniciar el tratamiento con albendazol $10 \mathrm{mg} / \mathrm{kg}$ /día vía oral previo a la cirugía y continuarlo durante al menos tres meses después ${ }^{12}$. Otro grupo de expertos recomiendan el uso de albendazol sólo en aquellos pacientes con múltiples quistes intracraneales o en otra localización, quistes residuales postquirúrgicos o en los casos de rotura intraquirúrgica ${ }^{10}$. En la serie que aquí presentamos, todos los pacientes recibieron tratamiento con albendazol antes, durante y después de la cirugía. La principal indicación fue tratar de evitar la siembra secundaria ante la ruptura del quiste y reducir el tamaño de la lesión.

Respecto al uso de praziquantel, estaría sugerido en aquellos casos donde se produce la rotura del quiste hidatídico en el momento de la cirugía con el fin de evitar la siembra de los protoescólices ${ }^{3,13}$. En nuestra serie de casos, se agregó prazicuantel en un solo paciente que presentó la rotura quística durante la cirugía.

Según datos del Ministerio de Salud de nuestro país, se notificaron 385 casos de hidatidosis durante el año 2010 , con una tasa de 0,95 casos por 100.000 habitantes $^{3}$. En la experiencia del Hospital Dr. J. P. Garrahan, los casos de hidatidosis cerebral representan el $12,7 \%$ de las hidatidosis atendidas $(6 / 47)^{14}$.

\section{Conclusión}

La hidatidosis cerebral es una patología poco frecuente y debe considerarse entre los diagnósticos diferenciales de lesiones tumorales quísticas de sistema nervioso central, tanto de localización única o múltiple, sobre todo en pacientes con antecedentes epidemiológicos relacionados y que provengan de zonas endémicas.

\section{Resumen}

La hidatidosis es una infección parasitaria causada por Echinococcus granulosus. El ser humano es un hospedero intermediario accidental. La localización más frecuente es la hepática. El compromiso cerebral es inusual, se describe que hasta $75 \%$ ocurre en población pediátrica. Se presenta una serie de seis niños con hidatidosis cerebral internados en el Hospital de Pediatría J. P. Garrahan. Todos presentaron compromiso neurológico al ingreso. Las imágenes mostraron lesiones quísticas únicas en el cerebro. No tuvieron compromiso de otros órganos. La serología fue negativa en todos los casos. El tratamiento fue médico-quirúrgico. La evolución clínica fue favorable sin secuelas en cinco de ellos y uno presentó una hemiparesia faciobraquiocrural derecha como secuela. Esta infección debe considerarse entre los diagnósticos diferenciales de lesiones tumorales quísticas del sistema nervioso central.

\section{Referencias bibliográficas}

1.- Clinton White A Jr, Fischer P R, Legua P. Chapter 226. Cestodes. Cherry J M, Harrison G J, Kaplan S L, Steinbach W J, Hotez P J. Feigin and Cherry's Textbook of Pediatric Infectious Diseases, $7^{\circ}$ edition. Philadelphia: Elsevier Saunders; 2009, p. 3030-48.

2.- Brunetti E, Kern P, Vuitton D A; Writing panel for the WHO-IWGE. Expert consensus for the diagnosis and treatment of cystic and alveolar echinococcosis in humans. Acta Trop 2010; 114: 1-16.

3.- Enfermedades infecciosas: diagnóstico de hidatidosis. Guía para el equipo de salud. Ministerio de Salud de la República Argentina. 2012. Disponible en: www.msal.gob.ar (accedido en enero de 2016).

4.- WHO/OIE. Manual on Echinococcosis in humans and animals: a public health problem of global concern. Disponible en: http://www.who. int/echinococcosis/resources/929044522X/en/ (accedido en febrero de 2016).

5.- Turgut M. Hydatidosis of central nervous system and its coverings in the pediatric and adolescent age groups in Turkey during the last century: a critical review of 137 cases. Childs Nerv Syst 2002; 18: 670-83.

6.- Kovoor J M, Thomas R D, Chandrashekkar H S, Jayakumar P N, Pillai S, Shankar S K. Neurohydatidosis. Australas Radiol 2007; 51: 406-11.

7.- Onal C, Unal F, Barlas O, Izqi N, Hepgul K, 
Turantan M I, et al. Long term follow up and results of thirty pediatric intracranial hydatid cysts: half a century of experience in the Department of Neurosurgery of the School of Medicine at the University of Istanbul (19522001). Pediatr Neurosurg 2001; 35: 72-81.

8.- Binesh F, Mehrabanian M, Navabii H. Primary brain hydatidosis. Br Med J Case Rep 2011; doi: 10.1136/bcr.06.2010.3099.

9.- Khaldi M, Mohamed S, Kallel J, Khouja N. Brain hydatidosis: report on 117 cases. Childs
Nerv Syst 2000; 16: 765-9.

10.- Duishanbai S, Jiafu D, Guo H, Liu C, Liu B, Aishalong M, et al. Intracraneal hydatid cyst in children: report of 30 cases. Childs Nerv Syst 2010; 26: 821-7.

11.- Tuzun Y, Solmaz I, Selgun G, Izci Y. The complications of cerebral hydatic cyst surgery in children. Childs Nerv Syst 2010; 26: 47-51.

12.- Mohindra S, Savardekar A, Gupta R, Tripathi M, Rane S. Varied types of intracranial hydatid cysts: radiological features and management techniques. Acta Neurochir 2012; 154: $165-72$.

13.- Bygott J M, Chiodini P L. Praziquantel: neglected drug? Ineffective treatment? Or therapeutic choice in cystic hydatid disease? Acta Tropic 2009; 111: 95-101.

14.- Monges J, Sosa F, Lubieniecki F, Taraturo A. Patología infecciosa pseudotumoral del sistema nervioso central en la infancia. Medicina Infantil 2000; 7: 90-4. 